\title{
DO PROXIMAL AND DISTAL GASTRIC TUMOURS BEHAVE DIFFERENTLY?
}

\author{
Tumores gástricos proximais e distais se comportam de forma diferente?
}

Laurence Bedin da COSTA ${ }^{1}$, Marcelo Garcia TONETO², Luis Fernando MOREIRA ${ }^{3}$

From the ${ }^{1}$ Programa de Pós-graduação em Medicina, Ciências Cirúrgicas, Universidade Federal do Rio Grande do Sul; '²epartamento de Cirurgia, Hospital São Lucas, Pontifícia Universidade Católica do Rio Grande do Sul; ${ }^{3}$ Departamento de Cirurgia, Hospital de Clínicas de Porto Alegre; ('Postgraduate Program in Medicine, Surgical Sciences, Universidade Federal do Rio Grande do Sul; '2Department of Surgery, Hospital São Lucas, Pontifícia Universidade Católica do Rio Grande do Sul; ${ }^{3}$ Department of Surgery, Hospital de Clínicas de Porto Alegre); Porto Alegre, RS, Brazil.

HEADINGS - Stomach neoplasms. Prognosis. Survivorship . Mortality. Lymph Node Excision.

\section{Correspondence:}

Luis Fernando Moreira

E-mail: lufmoreira@hcpa.edu.br

Financial source: none

Conflicts of interest: none

Received for publication: 16/06/2016 Accepted for publication: 06/07/2016

DESCRITORES - Neoplasias gástricas. Prognóstico. Sobrevida. Mortalidade. Excisão de Linfonodo.
ABSTRACT - Background: Although the incidence of gastric (adenocarcinoma) cancer has been decreasing over time, it is still one of the most common malignancies worldwide, and proximal tumours tend to have a worse prognosis. Aim: To compare surgical outcomes and prognosis between proximal - excluding tumours of the cardia - and distal gastric cancer. Methods: Out of 293 cases reviewed - 209 with distal and 69 with proximal gastric cancer - were compared for clinical and pathological features, stage, surgical outcome, mortality and survival. Results: Statistically, there was no significant difference between patients in both groups regarding mortality $(p=0.661)$, adjuvant chemotherapy $(p 0.661)$, and radiation $(p=1.000)$. However, there was significant difference in the degree of lymph node dissection employed $(p=0.002)$ and the number of positive lymph nodes resected $(p=0.038)$ between the two groups. The odds of death at five years for patients who had a D0 dissection was three times greater (odds ratio 2.78; $(95 \% \mathrm{Cl} 1.33-5.82)$ than that for patients who had a D2 dissection, while for patients who had a D1 dissection the odds ratio was only 1.41 (95\% Cl 0.71-2.83) compared to D2-dissected patients. Conclusion: Although no significant differences were found between proximal and distal gastric cancer, the increased risk of death in D0- and D1-dissected patients clearly suggests an important role of radical D2 lymph node dissection in survival.

RESUMO - Racional: Embora a incidência do câncer gástrico esteja diminuindo nas últimas décadas, ele ainda aparece como uma das neoplasias malignas mais comuns, e tumores proximais tendem a ter pior prognóstico. Objetivo: Comparar os resultados cirúrgicos e o prognóstico entre o câncer gástrico proximal, excluindo os tumores da cárdia e junção esofagogástrica, e o distal. Métodos: De 293 casos revistos - 209 distais e 69 proximais foram comparados quanto aos achados clínicos e patológicos, estágio, resultados cirúrgicos, mortalidade e sobrevida. Resultados: Estatisticamente não houve diferença entre pacientes em ambos os grupos quanto à mortalidade $(p=0.661)$, emprego de quimioterapia adjuvante $(p=0.661)$ e de radioterapia $(p=1.000)$. Entretanto, houve diferença significativa no grau de dissecção linfonodal empregada $(p=0.002)$ e no número de linfonodos positivos ressecados $(p=0.038)$ entre os dois grupos. A razão de chances para morte em cinco anos nos casos de dissecção D0 foi três vezes maior $(2,78$; IC95\% de 1,33 a 5,82) do que a D2, enquanto que para dissecção $\mathrm{D} 1$, ela foi apenas 1,41 vezes maior $(95 \% \mathrm{Cl} 0.71-2.83)$ quando comparado à $\mathrm{D} 2$. Conclusão: Ainda que não se tenha observado diferenças significativas entre o câncer gástrico proximal e o distal, o risco de morte aumentado nos casos de D0 e D1, claramente demonstra o papel preponderante da linfadenectomia radical D2 no tratamento dessa doença.

A Ithough the incidence of gastric cancer has decreased over the past decades, it still remains a relevant problem, being among the most common malignancies worldwide. According to the Globocan ${ }^{8} 2014$ project from the World Health Organization (WHO), there were approximately a million new gastric cancer cases worldwide (952,000 cases; $7 \%$ of all malignancies), ranking gastric cancer as the $5^{\text {th }}$ most common tumor in absolute numbers. In Brazil, data from the National Cancer Institute for 2016 place gastric cancer as the $4^{\text {th }}$ most common cancer in men $(12,870$ cases $)$ and the $6^{\text {th }}$ most common in women $(7,520$ cases). These figures place the stomach as the $6^{\text {th }}$ most frequently organ affected by cancer in Brazil ${ }^{10}$.

In the past, tumors originating in the cardia and in the gastro-esophageal junction were usually addressed as proximal gastric tumors, indistinctly. The anatomical structure of the proximal third of the stomach, where the serosa is partially developed, increasing the likelihood that these tumors will be diagnosed at a more advanced stage, may also be associated with unfavorable prognosis on proximal tumors'.

Moreover, there is no clear agreement on the link between mortality and tumor location in the stomach. Earlier papers considered prognostic and survival differences and stated that cancers originating in the cardia and in the gastro-esophageal junction tended to have a worse prognosis than those affecting more distal portions of the organ 13,27.

However, some authors have shown that, when cases are analyzed at sub-stages, outcomes are similar ${ }^{14,23,24}$. Still, excluding the tumors located either in the gastroesophageal junction with esophageal predominance or those affecting primarily the anatomical cardia (Siewert I and II types), no significant differences were observed on 
Nowadays, when there is a tendency to proximal migration of the primary tumor in the stomach, those parameters and differences between proximal and distal tumor need to be revised.

This study was designed to analyze both surgical and oncologic findings and outcomes of gastric cancer, and to compare differences between proximal (excluding tumors from esophagogastric origin) vs. distal lesions.

\section{METHODS}

This was a retrospective cohort study of 293 patients with adenocarcinoma of the stomach who underwent treatment at a university hospital (São Lucas Hospital in the Pontifícia Universidade Católica), located in the city of Porto Alegre, RS, Brazil, from January 2002 to January 2015. Patients' medical records from the Medical File Service of the institution were used as a research source. Cases with missing or incomplete data as well as those with histopathological findings other than adenocarcinoma and Siewert tumors types I and II were excluded from the analysis.

Preoperative endoscopy, pathology and surgical reports were reviewed, and tumor location was classified according to the criteria of the Japanese Gastric Cancer Association ${ }^{11}$. Proximal gastric cancer (PGC) was considered when the tumor extended from one point to more than $2 \mathrm{~cm}$ distal to the gastro-esophageal junction (Siewert type III) up to a crossing line between the left gastric artery and the end of the left gastroepiploic artery. Tumors below this crossing line were considered distal tumors. Demographic and epidemiological data, such as age, gender, tumor size, and number of dissected and involved lymph nodes were collected.

Tumor staging followed the guidelines of the TNM (tumornode-metastasis) system of the American Joint Committee on Cancer $(\mathrm{AJCC})^{7}, 7^{\text {th }}$ edition.

Postoperative surgical complications, excluding those that occurred after discharge, were classified according to the system proposed by Clavien, in 1992, and modified by Dindo, in $2004^{4}$.

\section{Statistical analysis}

Quantitative data were expressed as mean and standard deviation, or median and minimum-maximum ranges, according to variable distribution. As for qualitative data, absolute frequencies and percentage were used. Distal and proximal cases were analyzed using the Wilcoxon-Mann-Whitney test and the Chi-Square test, followed by analysis of residues, if needed. Cox Regression was used to compare survival between patients with proximal and distal tumors, respectively. The Kaplan-Meier method was used to estimate survival as a function of time, and the Log-Rank test was used for comparison of survival curves according to clinic-pathological characteristics. Statistical analysis was performed with the help of the Statistical Package for the Social Sciences (SPSS), version $18.0^{22}$, and the level of significance was set at $p<0.05$.

\section{RESULTS}

A total of 293 patients diagnosed with adenocarcinoma of the stomach were initially included in the study. A hundred and eighty-eight (64\%) were men and 105 (36\%) women. In 15 cases, initial tumor location could not be determined accurately enough to be included in the study. Five of them classified as multifocal, four as anastomotic recurrence, and in six cases, available data were not reliable. Therefore, 278 patients, 69 (25\%) of them with PGC and 209 (75\%) with distal gastric cancer (DGC) were included. Table 1 shows the clinic-pathological findings of the patients.
TABLE 1 - Clinic-pathological findings of patients depending on the location of primary tumor in the stomach

\begin{tabular}{|c|c|c|c|}
\hline Local tumor & $\begin{array}{c}\text { Proximal } \\
\mathrm{n}=69(24,8 \%)\end{array}$ & $\begin{array}{c}\text { Distal } \\
\mathrm{n}=209(75,2 \%)\end{array}$ & $\mathrm{p}$ \\
\hline & $\mathrm{n}(\%)$ & n (\%) & \\
\hline Male/Female & $40(58): 29(42)$ & 139 (66.5):70 (33.5) & 0.246 \\
\hline Age; years & 64.6 & 65.3 & 0.635 \\
\hline $\begin{array}{l}\text { Admission; average (sd); } \\
\text { days }\end{array}$ & $20.4(18.3)$ & $18.6(14.9)$ & 0.577 \\
\hline $\begin{array}{l}\text { Lesion; median (variation) } \\
\mathrm{cm}\end{array}$ & $7.2(0.4-18.0)$ & $4.6(0.4-14.3)$ & $<0.001$ \\
\hline $\begin{array}{l}\text { Resected lymph nodes } \\
\text { (median (variation) }\end{array}$ & $20.5(0-47)$ & $13.0(0-84)$ & $<0.001$ \\
\hline $\begin{array}{l}\text { Positive lymph nodes } \\
\text { (median (variation) }\end{array}$ & $4.0(0-46)$ & $2.0(0-40)$ & 0.038 \\
\hline $\begin{array}{l}\text { Metastases; median } \\
\text { (variation) months }\end{array}$ & $27.0(18-62)$ & $13.0(0-42)$ & 0.037 \\
\hline $\begin{array}{l}\text { AJCC Clinical stage } \\
0 \\
1 \mathrm{~A} \\
1 \mathrm{~B} \\
2 \mathrm{~A} \\
2 \mathrm{~B} \\
3 \mathrm{~A} \\
3 \mathrm{~B} \\
3 \mathrm{C} \\
4\end{array}$ & $\begin{array}{c}0(0) \\
9(13.4) \\
2(3) \\
2(3) \\
7(10.4) \\
4(6) \\
7(10.4) \\
25(37.3) \\
11(16.4)\end{array}$ & $\begin{array}{c}1(0.5) \\
27(13.7) \\
14(7.1) \\
13(6.6) \\
27(13.7) \\
11(5.6) \\
23(11.7) \\
37(18.8) \\
44(22.3)\end{array}$ & 0.168 \\
\hline $\begin{array}{l}\text { Level of differentiation } \\
\text { Well-differentiated (1) } \\
\text { Moderately } \\
\text { differentiated (2) } \\
\text { Poorlydifferentiated (3) }\end{array}$ & $\begin{array}{c}2(3.6) \\
16(28.6) \\
38(67.9)\end{array}$ & $\begin{array}{c}7(4.5) \\
74(47.1) \\
76(48.4)\end{array}$ & 0.038 \\
\hline $\begin{array}{l}\text { Subtype (Lauren) } \\
\text { Intestinal (1) } \\
\text { Diffuse (2) } \\
\text { Mixed (3) } \\
\text { Undetermined (4) }\end{array}$ & $\begin{array}{c}15(25.4) \\
29(49.2) \\
7(11.9) \\
8(13.6)\end{array}$ & $\begin{array}{l}51(29.8) \\
67(39.2) \\
25(14.6) \\
28(16.4)\end{array}$ & 0.625 \\
\hline $\begin{array}{l}\text { Limphadenectomy } \\
\text { D0 } \\
\text { D1 } \\
\text { D2 } \\
\text { Dx }\end{array}$ & $\begin{array}{c}12(20) \\
21(35) \\
26(43.3) \\
1(1.7)\end{array}$ & $\begin{array}{c}64(37.4) \\
71(41.5) \\
36(21.1) \\
0(0)\end{array}$ & 0.002 \\
\hline $\begin{array}{l}\text { Adjuvant chemotherapy } \\
\text { No } \\
\text { Yes }\end{array}$ & $\begin{array}{l}23(74.2) \\
8(25.8)\end{array}$ & $\begin{array}{l}74(67.9) \\
35(32.1)\end{array}$ & 0.661 \\
\hline $\begin{array}{l}\text { Adjuvant radiation } \\
\text { No } \\
\text { Yes }\end{array}$ & $\begin{array}{l}22(73.3) \\
8(26.7)\end{array}$ & $\begin{array}{l}80(74.1) \\
28(25.9)\end{array}$ & 1.000 \\
\hline $\begin{array}{l}\text { Death } \\
\text { Yes } \\
\text { No }\end{array}$ & $\begin{array}{l}14(31.8) \\
30(68.2)\end{array}$ & $\begin{array}{l}45(34.6) \\
85(65.4)\end{array}$ & 0.661 \\
\hline
\end{tabular}

In the PGC group, the median range number of lymph nodes removed was $20(0-47)$, significantly lower $(p<0.001$ than in the DGC group, which was $13(0-84)$. Positive range lymph nodes were also lower in the PGC group as compared to the DGC group, $2(0-40)$, and $4(0-46)$, respectively $(p=0.038)$. As for lymph node status, the probability of being alive in five years was $48 \%(11 \%)$ for $N 1(n=34), 37 \%(11 \%)$ for $N 2$ $(n=41)$, and $23 \%(7 \%)$ for N3 $(n=73)$, with no significant difference between these groups, statistically.

Patients who underwent D0 lymph node dissection had a median survival of 26 months, which was less than that of patients who underwent D1 dissection (54 months) or D2 dissection (63 months). Moreover, for patients with a D0 lymph node dissection, the cumulative probability of being alive in five years was $30 \%(8 \%)$, while for those who had a D1 or D2 dissection, these probabilities were $48 \%$ (7\%) and 53\% (9\%), respectively. However, differences in survival between the levels of lymph node dissection were not statistically significant.

Figure 1 shows the overall survival curve according to 
the level of lymph node dissection performed.

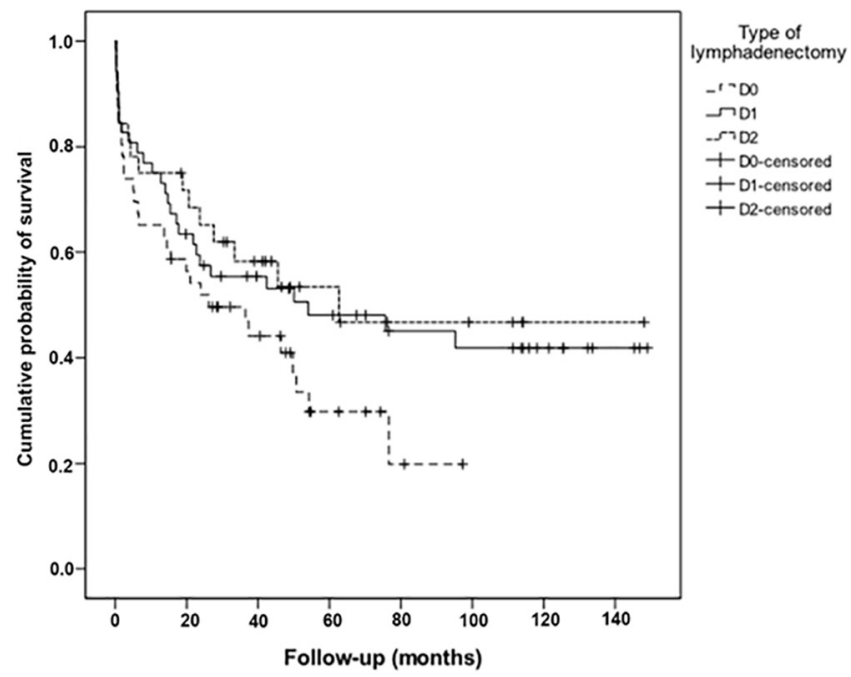

FIGURE 1 - Survival according to the type of lymphadenectomy

As expected, the majority of patients in both groups had advanced tumors. Proximal tumors were larger in size $(p<0.001)$, presented with a higher number of positive lymph nodes ( $p=0.038)$, and were significantly less differentiated, as for histopathology, than distal lesions $(p=0.038)$. Early lesions (T1) accounted for $19 \%$ of all tumors (16\% of PGC and $20 \%$ of DGC). On the other hand, 20\% of patients had disseminated tumor already (M1) at diagnosis, also $16 \%$ and $20 \%$, respectively.

Overall, average (SD) tumor size was $5.8(3.7 \mathrm{~cm})$, ranging from $4 \mathrm{~mm}$ to $20 \mathrm{~cm}$. Average (SD) size in the DGC and PGC groups were $7.4(4.3 \mathrm{~cm})$ and $5(2.8 \mathrm{~cm})$, respectively $(p<0.001)$. Tumor size was directly related to mortality, where patients with tumors larger than $8 \mathrm{~cm}$ in diameter had a significantly shorter survival than those with lesions smaller than $5 \mathrm{~cm}(6$ vs. 50 months; $p<0.001)$. Furthermore, patients with tumors larger than $8 \mathrm{~cm}$ died earlier within 60 months (81\% vs. 53\%) as compared to those patients with lesions smaller than $5 \mathrm{~cm}$. The probability of being alive in five years was $14 \%(4.7 \%)$ for patients with tumors larger than $8 \mathrm{~cm}$, while for patients with tumors smaller than $5 \mathrm{~cm}$, this probability was $42 \%$ (7\%). Statistically, the effect of tumor size on survival did not differ between proximal and distal locations.

As for factors related to survival, T4 tumors were found to be strongly positively associated with N3 lymph node involvement $(p=0.001)$, where more than half $(58 \%)$ of T4 cases were N3. The majority of T2/T3 tumors were associated with a lower lymph node involvement (N1 and N2), and only a small percentage of them (8\%) were N3.

Patients with T4 tumors $(n=158)$ had the worst outcomes, and the probability of being alive in five years was 32\% (5.4\%). When cases with tumors confined into the muscle or up to the serosa $(T 2 / T 3)$ were analyzed together $(n=47)$, the probability of being alive in five years was $47 \%(11.4 \%)$.T4 cases had a median survival of only 21 months, while T2/T3 cases had a median survival of 54 months, but this difference was not statistically significant. Patients with T4 tumors presented 2.17 times $[0.94-5.02 ; 95 \% \mathrm{Cl}]$ more chances to die within five years than patients with lesions with less impairment of the organ wall.

There were postoperative complications in $25 \%$ of patients with PGC and $23 \%$ of patients with DGC. The most common complication in both groups was pneumonia, which affected $30(14 \%)$ patients, followed by fistula in $17(8 \%)$, sepsis in 8 $(4 \%)$, and wound infection in 6 (2.8\%). Intra hospital mortality rate was $5 \%(n=6)$.

Overall recurrence was $37 \% ; 48$ out of 128 cases were followed up till the end of the study, being peritoneal surface $(n=29)$ and liver $(n=11)$ the most common sites. There was no statistically significant difference between the two groups regarding the use of adjuvant therapy, where 11 (8\%) patients receiving chemotherapy alone and 31 (23\%) receiving also radiotherapy did relapse.

Survival rates were calculated based on the follow-up of 278 patients, and cumulative probability of being alive in five years was estimated in 35\% (7.4\%) for patients with PGC and $32 \%$ (4.5\%) for patients with DGC. This difference was not statistically significant between both groups either.

Figure 2 shows the overall survival curve for patients in the two groups throughout study period. When adjusted for tumor size and degree of lymph node dissection performed, the higher the number of positive lymph nodes, the greater the mortality $(p=0.007)$.

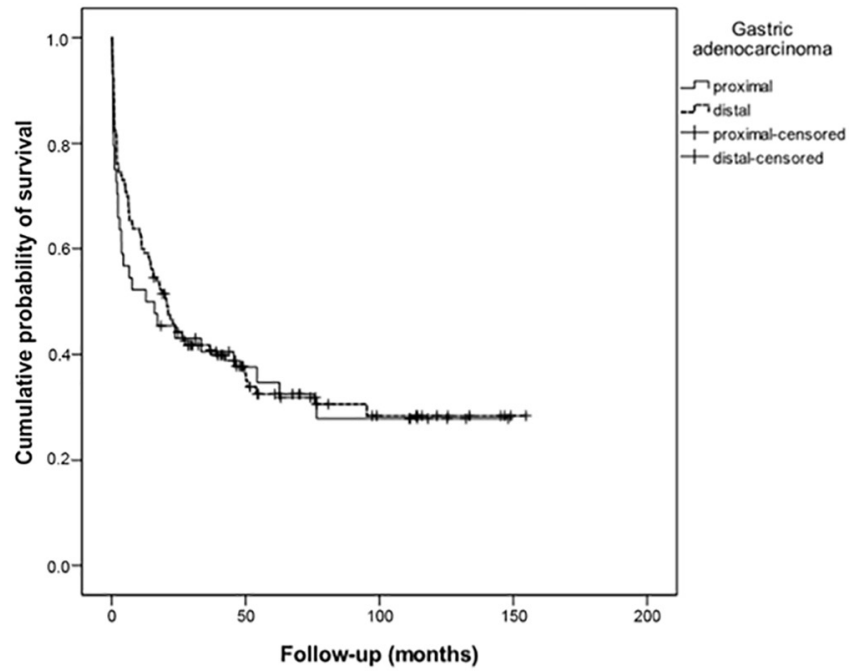

FIGURE 2 - Survival according to the location of primary tumor

On multivariate analysis of survival at 60 months, considering tumor location (proximal vs. distal), T4 category (T4 vs. T2/T3), N category (N0 vs. N1 vs. N2), and the degree of lymphadenectomy (D0 vs. D1 vs. D2) as related factors, the only significant risk factor, following adjustments, was the degree of lymphadenectomy performed $(p=0.018)$.

Patients who had a D0 lymphadenectomy presented 2.8 [95\% Cl; 1.33-5.82] times higher death risk in five years than D2dissected patients, while patients who had a D1 lymphadenectomy presented 1.4 [95\% $\mathrm{Cl} ; 0.71-2.83]$ times higher death risk in five years than the D2 death cases by the end of the same period of time.

Overall mortality was $41 \%(n=115)$, where $30(43 \%)$ and 85 (41\%) patients died in the PGC and DGC groups, respectively. Out of 69 patients with PGC and 209 patients with DGC, 39 (57\%) and 124 (59\%) were still alive at the end of the study period. There was no significant difference in mortality between the two groups.

Besides that, there was no difference in mortality based on location of primary lesion, as cumulative probability of being alive in five years was 35\% (14.5\%) for the PGC group, and $32 \%(9 \%)$ for the DGC group.

\section{DISCUSSION}

It is well known that aggressiveness of gastric cancer depends on a number of factors, including wall invasion pattern and lymph node status, which are the two most important findings to estimate prognosis and to guide decision making ${ }^{17,19}$. Furthermore, the presence of regional lymph node metastases alone is the most important independent prognostic factor for survival in these patients ${ }^{3,6}$. Although proximal lesions did show deeper invasion and higher lymph node involvement, 
outcomes did not differ significantly between the two groups

Does tumor size matter? In patients with other types of cancer, such as breast or lung cancer, tumor size is still an important predictor. In gastric cancer, however, the prognostic value of tumor size remains controversial ${ }^{16,29}$. Some authors showed that tumor size can be an important factor as for aggressiveness ${ }^{9,30}$. This is consistent with the present study, where a direct relationship was found between lesion diameter and aggressiveness. The larger the tumor, the more aggressive, with deeper invasion in stomach wall and higher degree of lymph node involvement. Nevertheless, proximal lesions were significantly larger than distal ones.

Treatment of gastric cancer is multi-factorial, but surgery still plays a primary role in management, since it is the only approach that can lead to cure. The stage at which the disease is detected plays a crucial role in treatment choice. The use of chemotherapy or radiotherapy combined with surgery is well established, with clear benefits in survival and disease progression. This approach was strengthened especially after the classic study by Macdonald et al. in $2001^{18}$, with the combination of preoperative chemotherapy and postoperative radiation, which showed an increase in overall survival from 27 to 36 months, compared to surgery alone. Cunningham, in $2006^{5}$, showed improvement in overall and progression-free survival with per-operative chemotherapy.

Nevertheless, prognosis of gastric cancer is still quite dismal - despite constant improvements in adjuvant therapy with the development of new drugs and association of target therapy that have, und oubtedly, improved survival-, especially for those cases with serosal invasion. In such cases, even after radical resection, about $20-40 \%$ of the patients die due to recurrence ${ }^{2,20}$ and present peritoneal dissemination, which is, in fact, the main cause of treatment failure, and where serosal invasion is a predisposing factor ${ }^{15}$. In this study, no difference was found on peritoneal recurrence according to primary tumor location, and this was not affected by either preoperative or postoperative adjuvant treatment.

Overall survival in five years for patients operated on for advanced gastric cancer differs among countries and medical institutions, but it is generally below $30 \%$ in Western countries, such as those of Europe and in the United States ${ }^{11,28}$. In Asian countries, such as Japan and South Korea, survival is significantly higher, reaching approximately $70 \%^{21}$. In the present study, survival was identical in both groups, with a rate of $37 \%$ for PGC and $36 \%$ for DGC, consistent with published results.

Despite therapeutic advances over the past decades, especially regarding adjuvant therapy, mortality of gastric adenocarcinoma remains high. The results of the present study showed no significant differences in surgical outcome or prognosis between proximal and distal lesions. As expected and similar to previous studies, the degree of lymph node involvement and tumor size were independent factors that affected survival.

\section{CONCLUSION}

Although significant differences between distal and proximal gastric tumors have not been observed, the increased risk of death in D0 and D1-dissected cases clearly suggests a main role of radical D2 lymphadenectomy in the treatment of this disease.

REFERENCES

1. Bruno L, Nesi G, Montinaro F, Carassale G, Lassig R, Boddi V, et al. Clinicopathologic findings and results of surgical treatment in cardiac adenocarcinoma. J Surg Oncol. 2000 May;74(1):33-5.

2. Carboni F1, Lepiane $P$, Santoro R, Lorusso R, Mancini $P$, Sperduti I, et al ExtendedmultiorganresectionforT4gastriccarcinoma:25-yearexperience. J Surg Oncol. 2005 May 1;90(2):95-100.
3. ChaeS,LeeA, LeeJH.Theeffectiveness ofthenew(7th)UICCN classification in the prognosis evaluation of gastric cancer patients: a comparative study between the 5th/6th and 7th UICC N classification. Gastric Cancer. 2011 Jun;14(2):166-71.

4. Clavien PA, Barkun J, de Oliveira ML, Vauthey JN, Dindo D, Schulick RD, et al. The Clavien-Dindo classification of surgical complications: five-year experience. Ann Surg. 2009 Aug;250(2):187-96.

5. Cunningham D, Allum WH, Stenning SP, Thompson JN, Van de Velde CJ Nicolson $\mathrm{M}$, et al. Perioperative chemotherapy versus surgery alone for resectablegastroesophageal cancer.NEnglJ Med.2006 Jul6;355(1):11-20.

6. Deng J, Liang $H$, Sun D, Wang D, Pan Y. Suitability of 7th UICC N stage for predicting the overall survival of gastric cancer patients after curative resection in China. Ann Surg Oncol. 2010 May;17(5):1259-66.

7. Edge SB, Byrd DR, Compton CC, Fritz AG, Greene FL, Trotti A. AJCC cancer staging manual. New York: Springer; 2010.

8. Ferlay J, Soerjomataram I, Ervik M, Dikshit R, Eser S, Mathers C, et al. GLOBOCAN 2012 v1.0, Cancer Incidence and Mortality Worldwide: IARC CancerBaseNo.11[Internet].Lyon,France:InternationalAgencyforResearch onCancer;2013 [cited2015Nov09].Availablefrom:http://globocan.iarc.fr.

9. Giuliani A, Caporale A, Di Bari M, Demoro M, Gozzo P, Corona M, et al. Maximum gastric cancer diameter as a prognostic indicator: univariate and multivariate analysis. J Exp Clin Cancer Res. 2003 Dec;22(4):531-8.

10. Gomes da Silva JA. [National Institute of Cancer] 2014 estimates: incidence of cancer in Brazil [Internet]. Rio de Janeiro: INCA; 2014 [cited 2015 Nov 09].Availablefrom:http://www.inca.gov.br/bvscontrolecancer/publicacoes/ Estimativa_2014.pdf

11. HowladerN, RiesLA,StinchcombDG,EdwardsBK.Theimpactofunderreported VeteransAffairs dataonnational cancerstatistics:analysisusing populationbased SEER registries. J Natl Cancer Inst. 2009 Apr 1;101(7):533-6.

12. Japanese Gastric Cancer Association. Japanese classification of gastric carcinoma: 3rd English edition. Gastric Cancer. 2011 Jun; 14(2):101-12.

13. Kim DY, Joo JK, Ryu SY, Park YK, Kim YJ, Kim SK. Clinicopathological characteristics and prognosis of carcinoma of the gastric cardia. Dig Surg. 2006;23(5-6):313-8.

14. Kunisaki C, Akiyama H, Nomura M, Matsuda G, Otsuka $Y$, Ono $H$, et al. Surgical outcomes forearlygastric cancerintheupperthird of thestomach. J Am Coll Surg. 2005 Jan;200(1):15-9.

15. Kunisaki C, Akiyama H, Nomura M, Matsuda G, Otsuka Y, Ono HA, et al. Surgical outcomes in patients with T4 gastric carcinoma. J Am Coll Surg. 2006 Feb;202(2):223-30.

16. Kunisaki C, Makino H, Takagawa R, Oshima T, Nagano Y, Kosaka T, et al. Tumor diameter as a prognostic factor in patients with gastric cancer. Ann Surg Oncol. 2008 Jul;15(7):1959-67.

17. LeeIS, Park YS, Ryu MH, Song MJ, YookJH, OhST, etal. Impact of extranodal extension on prognosis in lymph node-positive gastric cancer. Br J Surg. 2014 Nov; 101(12):1576-84

18. MacdonaldJS,SmalleySR, BenedettiJ,HundahISA, EstesNC,Stemmermann $\mathrm{GN}$, et al. Chemoradiotherapy after surgery compared with surgery alone for adenocarcinoma of the stomach or gastroesophageal junction. $\mathrm{N}$ Engl J Med. 2001 Sep 6;345(10):725-30.

19. Mita K, Ito H, Fukumoto M, Murabayashi R, Koizumi K, Hayashi T, et al. Surgical outcomes and survival after extended multiorgan resection for T4 gastric cancer. Am J Surg. 2012 Jan;203(1):107-11.

20. Moriguchi S, Maehara Y, Korenaga D, Sugimachi K, Nose Y. Risk factors which predict pattern of recurrence after curative surgery for patients with advanced gastric cancer. Surg Oncol. 1992 Oct;1(5):341-6.

21. Park JY, von Karsa L, Herrero R. Prevention strategies for gastric cancer: a global perspective. Clin Endosc. 2014 Nov;47(6):478-89

22. PASW Statistics for Windows, Version 18.0. Chicago: SPSS; [2007].

23. Piso $P$, Werner $U$, Lang $H$, Mirena $P$, Klempnauer J. Proximal versus distal gastric carcinoma - what are the differences? Ann Surg Oncol. 2000 Aug;7(7):520-5.

24. Ramagem, CAG, et al. Comparison of laparoscopic total gastrectomy and laparotomic total gastrectomy for gastric cancer. $A B C D$, arq. bras. cir. dig., 2015, vol.28, no.1, p.65-69. ISSN 0102-6720

25. Sanchez-Bueno F, Garcia-Marcilla JA, Perez-Flores D, Perez-Abad JM, Vicente $R$, Aranda $F$, et al. Prognostic factors in a series of 297 patients with gastric adenocarcinoma undergoing surgical resection. Br J Surg. 1998 Feb;85(2):255-60.

26. Soreide JA, van Heerden JA, Burgart LJ, Donohue JH, Sarr MG, Ilstrup DM. Surgical aspects of patients with adenocarcinoma of the stomach operated on for cure. Arch Surg. 1996 May;131(5):481-6; discussion486-8.

27. Talamonti MS, Kim SP, Yao KA, Wayne JD, Feinglass J, Bennett $C L$, et al. Surgical outcomes of patients with gastric carcinoma: the importance of primary tumor location and microvessel invasion. Surgery. 2003 Oct;134(4):720-7; discussion 727-9.

28. Verdecchia A, Francisci S, Brenner H, Gatta G, Micheli A, Mangone L, et al. Recentcancersurvival inEurope:a2000-02 periodanalysisofEUROCARE-4 data. Lancet Oncol. 2007 Sep;8(9):784-96.

29. Zilberstein, Bruno et al. Resultados da gastrectomia D2 para o câncer gástrico: dissecção da cadeia linfática ou ressecção linfonodal múltipla? ABCD, arq. bras. cir. dig., Set 2012, vol.25, no.3, p.161-164. ISSN 0102-6720

30. ZuH,WangF,MaY,XueY.Stage-stratifiedanalysisofprognosticsignificance of tumor size in patients with gastric cancer. PLoS One. 2013;8(1):e54502. 